\title{
SABERES DOCENTES: AS PERSPECTIVAS PROFISSIONAIS DE PROFESSORES DE ENSINO TÉCNICO
}

\author{
TEACHING KNOWLEDGE: THE PROFESSIONAL PERSPECTIVES OF TECHNICAL \\ TEACHING TEACHERS
}

\author{
André Luís Pinto de Oliveira ${ }^{1}$ \\ Alessandro Segala Romano ${ }^{2}$ \\ Rosália Maria Netto Prados ${ }^{3}$
}

RESUMO: Este artigo discute as perspectivas profissionais de professores que atuam em uma instituição pública de educação técnica e tecnológica do Estado de São Paulo. Baseia-se em estudos sobre saberes docentes, educação profissional e formação de professores. Seus objetivos são descrever os saberes que constituem o professor e analisar suas perspectivas profissionais. No desenvolvimento desta discussão, propõe-se, de acordo com uma metodologia de abordagem qualitativa a partir dos saberes docentes estudados, uma análise das perspectivas dos professores em relação à sua profissão. Nesta análise, foi aplicado o programa IRAMUTEQ software de análise de conteúdo, para identificar e visualizar os saberes docentes e suas perspectivas profissionais. Os estudos mostraram que a profissão docente em educação profissional requer vivência em sala de aula, bem como nas demais atividades profissionais, além de atualização constante de conhecimentos.

Palavras-chave: Professor. Educação Profissional. Saberes docentes.

ABSTRACT: This article discusses the professional perspectives of teachers who work in a public institution of technical and technological education in the State of São Paulo. It is based on studies on teaching knowledge, professional education and teacher training. Its objectives are to describe the knowledge that constitutes the teacher and to analyze his professional perspectives. In the development of this discussion, it is proposed, according to a qualitative approach methodology based on the teaching knowledge studied, an analysis of the perspectives of teachers in relation to their profession. In this analysis, the IRAMUTEQ program, content analysis software, was applied to identify and visualize teaching knowledge and their professional perspectives. Studies have shown that the teaching profession in professional education requires experience in the classroom, as well as in other professional activities, in addition to constant updating of knowledge.

Keywords: Teacher. Professional Education. Teaching knowledge.

\footnotetext{
1 Mestrando em Gestão e Desenvolvimento da Educação Profissional, Centro Estadual de Educação Tecnológica Paula Souza (CEETEPS); Orcid https://orcid.org/oooo-ooo2-2686-III. e-mail alp.oliveiraoı@gmail.com.

2 Mestrando em Gestão e Desenvolvimento da Educação Profissional, Centro Estadual de Educação Tecnológica Paula Souza (CEETEPS); Orcid https://orcid.org/oooo-ooor-9741-7483. e-mail alesromano@yahoo.com.br.

3 Professora pesquisadora do Programa de Mestrado em Gestão e Desenvolvimento da Educação Profissional, Centro Estadual de Educação Tecnológica Paula Souza (CEETEPS); e-mail: rosalia.prados@gmail.com.
} 


\section{INTRODUÇÃO}

As redes de formação profissional e tecnológica têm se expandido nos últimos anos, de maneira mais intensa nas modalidades de Ensino Técnico de nível médio, já que se busca suprir a falta de alguns profissionais capacitados para a docência, a fim de atender a alguns eixos produtivos da economia. Com a expansão dos postos de ensino, também ampliam-se os profissionais que exercem a docência em educação profissional.

Assim, a formação de professores ${ }^{4}$ para o Ensino Médio Profissional tem sido assunto de desafio às autoridades e aos gestores que cuidam dos currículos educacionais (PETEROSSI, 2017). Como uma orientação para a proposta e desenvolvimento desta discussão, o problema direcionador se apresenta no seguinte questionamento: "O que se diz a respeito da profissão docente em educação profissional?”

$\mathrm{Na}$ organização deste estudo, propõe-se uma pesquisa, de abordagem qualitativa, sobre saberes do professor em educação profissional. Para o desenvolvimento desta pesquisa, a fundamentação teórica tratou de estudos sobre a educação profissional, formação de professores e de estudos sobre os saberes docentes e formação profissional.

O objetivo é realizar uma análise das perspectivas sobre a profissão docente. Neste estudo, analisar-se-á a concepção do professor como profissional; e como a profissão é vista atualmente, na área da educação profissional.

\section{Os Saberes Docentes}

Espera-se, em geral, que os professores que atuam na esfera da educação profissional apresentem uma experiência na área prática da sua profissão de formação. No momento, porém, em que esses se inserem em uma instituição de ensino profissional apoiam-se em modelos pedagógicos que fizeram parte de sua formação acadêmica, por seus próprios professores e experiências.

Muitos desses professores não dominam os saberes que fundamentam sua prática, como mediadores do processo de ensino e aprendizagem, mas atuam em diferentes cursos de formação profissional, assim como outros que lecionam em diferentes instituições, também não obtiveram formação específica pedagógica que os capacitasse a tal atividade. E observa-se que os profissionais de mercado, com grande experiência para compartilharem, não dominam os saberes da docência. Existe "aquele que domina o conhecimento específico da sua área ou disciplina, mas que não necessariamente sabe ensinar" (PIMENTA; ALMEIDA, 2009 p. 24).

No que se refere aos conteúdos, os conhecimentos não podem ser desprezados, pois profissionais da educação têm seus saberes gerados no próprio processo de ensinar, mas possuem,

\footnotetext{
${ }^{4}$ Doravante o substantivo professor será utilizado para representar ambos os gêneros. O mesmo acontece em sua forma plural.
} 
também, saberes que englobem conhecimentos, competências e habilidades inerentes à função docente. De acordo com Tardiff (2014), tais conhecimentos dão corpo e estrutura à aula a ser ministrada.

Muitos docentes, de cursos de formação profissional técnica e tecnológica, necessitam buscar bases pedagógicas em diferentes fontes, como por exemplo, educadores de formação que possam contribuir com novas propostas metodológicas e de compreensão sobre o processo de ensino e aprendizagem. Considera-se, assim, a necessidade de se pensar no ambiente educacional "escola", como um espaço de construção do saber, não somente do aluno, mas também do docente. A escola é vista como um local, em que se desenvolvem competências, pelo ato de refletir, além de questionamentos e envolvimento dos conhecimentos frente à sociedade (ALARCÃO, 2003).

São abrangentes as possibilidades de conhecimentos e interações sociais que se refletem no profissional que se insere nas salas de aulas para ensinar nos dias de hoje. Segundo Nóvoa (2002), durante o processo de formação docente, três grupos de competências são fundamentais para a prática profissional: saber relacionar e saber relacionar-se; saber organizar e saber organizar-se; e, por fim, saber analisar e saber analisar-se.

Assim é possível verificar que o autor chama a atenção para uma ação que necessita ser avaliada de maneira contínua e reflexiva: a ação docente. Nesta, o conjunto de teorias, práticas e experiência são pertinentes no processo de ensino e aprendizagem não somente de seus alunos, mas também dele próprio como docente, ainda que, para Nóvoa (2002), exista dificuldade em se formalizar e conceituar esses saberes.

Segundo Pimenta (2005), alguns saberes são inerentes à formação docente: saberes da experiência, saberes do conhecimento e saberes pedagógicos, pois um professor é composto de saberes múltiplos que formatam sua identidade, uma vez que seus conhecimentos de conteúdo, suas experiências de vida em ambientes educacionais diversos e como ele ministra suas aulas convergem num projeto único formativo que, por sua vez, coloca-o na posição de professor. E acrescenta que a formação docente envolve auto formação, a partir da reelaboração constante dos saberes que os professores realizam em sua prática, além do confronto de suas experiências em diferentes contextos escolares de instituições onde atuam.

Esse processo contínuo é uma das marcas da identidade docente. Segundo Tardif (2014), a identidade de uma pessoa traz marcas de sua própria atividade e uma parte considerável de sua existência é marcada por sua atuação profissional.

Este sujeito, ao se formar professor, forma também sua identidade de pertencimento, o que o faz tornar-se cada vez mais professor. Segundo Rose, "o trabalho pode fazer que alguém se sinta parte de alguma coisa maior do que ele próprio [...] e pode contribuir para um sentido de auto identidade" (ROSE, 2007, p. 4I). 
$\mathrm{Na}$ contemporaneidade, com o avanço das tecnologias aplicadas às mais diferentes áreas, evidencia-se que cursos de formação, de um modo geral, não fornecem todos os subsídios para a capacitação de profissionais aptos a assumirem as responsabilidades em sua atuação, seja ela qual for. Sabe-se que além da formação inicial, as experiências, compartilhamentos e atualizações são essenciais ao ideal formativo em qualquer carreira profissional e também para a docência.

Tardif (2014) analisa a trajetória e a formação de um professor. Para isso, põe em discussão as competências, habilidades e os saberes que um professor deve ter para a boa realização de sua atuação profissional. $\mathrm{Na}$ sociedade atual, é relevante debruçar-se em análises sobre a formação do professor, razões e princípios da docência, bem como sobre os sistemas, nos quais esses estão inseridos e constroem seu próprio percurso profissional (SANTOMÉ, 200I).

O saber do professor em seu trabalho, segundo Tardif (2014), inicia-se com um questionamento sobre o saber-fazer docente, para algumas análises sobre a modificabilidade do sujeito a partir de sua profissão, ou trabalho.

se o trabalho modifica o trabalhador e sua identidade, modifica também, sempre com o passar do tempo, o seu "saber trabalhar". De fato, em toda a ocupação, o tempo surge como fator importante para compreender os saberes dos trabalhadores, uma vez que trabalhar remete a aprender a trabalhar, ou seja a dominar progressivamente os saberes necessários à realização do trabalho. (TARDIF, 2014. p. 57)

Tardif (2014), no entanto, defende que o saber-fazer de uma profissão não vem de forma 82 imediata, como se programada corporal e mentalmente. É o tempo e a dominação progressiva das habilidades que constituem os saberes de uma profissão.

os saberes ligados ao trabalho são temporais, pois são construídos e dominados progressivamente durante um período de aprendizagem variável, de acordo com cada ocupação. Essa dimensão temporal decorre do fato de que as situações de trabalho exigem dos trabalhadores conhecimentos, competências, aptidões e atitudes específicas que só podem ser adquiridas e dominadas em contato com essas mesmas situações (TARDIF, 2014. p. 58).

As relações entre tempo, trabalho e aprendizagem dos saberes profissionais dos professores são importantes. Segundo o autor, apenas os saberes mobilizados e empregados durante os momentos quotidianos do trabalho docente para a resolução de problemas e para dar sentido a determinadas situações é o que constrói o saber-fazer da profissão-professor. Além disso, Tardif considera que os saberes são plurais, heterogêneos, porque acabam por vir de fontes variadas, de diferentes naturezas e bastante pautados no saber- ser de cada profissional.

Um professor é alguém que sabe de alguma coisa e que se dispõe a transmitir algo, ou um saber, a outra pessoa. Aliás, para Tardif (2014), o professor ideal é o profissional que conhece o mote do seu trabalho, sua matéria, currículo, conteúdo e disciplina que devem ser ministrados por este profissional. $\mathrm{E}$ o profissional professor também deve ter conhecimentos relacionados às ciências da 
docência e da pedagogia, além de se utilizar de tais conhecimentos para desenvolver um saber prático que é baseado na experiência que desenvolve nas atividades com os alunos.

Para Santomé (200I), uma parte dos professores tem optado por ideologias de profissionalismo. Esses professores consideram-se trabalhadores do ensino. E apresentam uma ruptura em relação ao processo de formação, considerando-se portadores dos saberes científicos necessários para a prática da educação. Ao se refletir sobre a profissionalização docente, busca-se uma melhor reputação à valorização daqueles que optam se dedicar à docência (SANTOMÉ, 200I).

Para Tardif (2014), essa classe de professores são os chamados pragmáticos, cujos saberes empregados para o ensino estão fundamentalmente ligados ao trabalho e à pessoa do trabalhador. Para esses professores, os saberes são práticos e a cognição é condicionada à sua atividade. Em outras palavras, ela está à serviço da sua ação.

Além dos pragmáticos, segundo Tardif (2014), há outras duas classes fundantes, instituídas a partir do que ele chama de fundamentos do ensino. Assim, contrapondo-se e, ao mesmo tempo, complementando-se aos pragmáticos existem os existenciais, para os quais os professores não podem ser definidos por representações epistemológicas, mas são produtos de relações emocionais, afetivas, pessoais e interpessoais. Para os fundamentos existenciais, o professorado processa informações extraídas através do seu sistema cognitivo, buscando fatores em sua memória, por exemplo, para organizar novas informações.

Em um esquema dialético surge o terceiro fundamento do ensino, a classe dos professores sociais. Os fundamentos do ensino também são sociais, porque os professores são provindos e carregam consigo marcas de fontes sociais diversas. Cada profissional professor aplica, às suas atividades, traços daquilo que experienciou e aprendeu em sua família, escola, formação universitária ou em outros campos de trabalho que possa já ter preenchido. Além disso, cada profissional carrega estigmas de tempos sociais diferentes, em grupos sociais diferentes o que, decerto, gera consciências profissionais diferentes (TARDIF, 2014).

Quanto a esse assunto, questiona Franco (2012), se a prática docente é a mesma coisa que prática pedagógica. Para a autora ambas as práticas podem apenas ser consideradas sinônimos, quando existe intencionalidade na ação. Ou seja, para a autora o bom profissional professor deve saber qual é o sentido da sua aula e como tal atividade contribuirá para a formação do aluno, de forma a integrá-la e expandi-la. Esse profissional tem consciência do significado de sua ação e, por esta razão, consegue dialogar com as necessidades do aluno, ele insiste na aprendizagem e faz questão de acompanhar o processo, pois acredita que o que está propondo será importante para o aluno (FRANCO, 2012).

Questionamentos como: que saberes são esses, transmitidos pelos professores? Esses saberes são gerados pelo professor? Ou por outros grupos, nos quais o professor transita e são apenas 
transmitidos por ele? Ainda, segundo Tardif (2014), tais questões sugerem que exista uma relação problemática entre a conceituação do profissional professor e seus saberes e, assim, sem o intuito de gerar respostas completas e definitivas para essas questões, destaca alguns tipos diferentes de saberes docentes: os saberes da formação profissional (das ciências da educação e da ideologia pedagógica), os saberes disciplinares, os saberes curriculares e os saberes experienciais. De acordo com Tardif (2014, p. 39), "os saberes são elementos constitutivos da prática docente".

Os professores se constituem como um grupo social e profissional, cuja existência está intrinsicamente ligada à capacidade de dominar, integrar e conduzir esses saberes para a sua prática, enquanto docente. Em suma, o profissional professor deve ser capaz de fazer múltiplas articulações entre práticas e saberes, de forma a conseguir sintetizar e codificar as matérias de sua formação para seus alunos (saberes disciplinares); entender e pôr em prática os discursos, objetivos, sistemas e métodos da instituição ao qual é contratado dentro do seu espectro pedagógico (saberes curriculares) e, por fim, amalgamar conteúdos científicos e sistemas institucionais à sua bagagem experiencial adquirida pelo seu trabalho cotidiano (saberes experienciais) (TARDIF, 20I4).

Para Tardif (2014), o ofício da docência está além de ser uma categoria inocente, neutra, uma prática utilitária. Ao contrário disso, a docência porta consigo questões sociais importantes que ilustram as tensões e os problemas de uma época.

Nesse sentido, as ideias de Tardif são pertinentes em relação às de Delors (2006), que trata

da Educação, no século XXI, em que se destacam princípios voltados à responsabilidade, quanto ao desenvolvimento de competências socioemocionais, dentre outras, no processo de formação que, além de preparar um indivíduo autônomo, possibilite-se que este concilie seus compromissos profissionais, pessoais e acadêmicos. Desde então, as políticas educativas são consideradas não só um processo permanente de enriquecimento dos conhecimentos, das competências, do saber-fazer, mas também uma via privilegiada de construção da própria pessoa e sociedade.

\section{A Formação do Professor da Educação Profissional}

Na docência, bem como é o objetivo de qualquer bom profissional, o professor busca ser o mais competente em seu ofício. Segundo Zabala, a competência no ofício "se consegue [...] mediante o conhecimento e a experiência: o conhecimento das variáveis que intervêm na prática e a experiência para dominá-las" (ZABALA, 1998, p. 13). Para Tardif (2014) é fato que quando um professor é interrogado sobre os seus saberes e a sua relação com os saberes, os seus discursos apontam para categorias que se definem em práticos ou experienciais.

Entretanto, complementa Tardif (2014), a prática docente não é somente um objeto provindo da ciência da educação, mais do que isso, é uma atividade capaz de mobilizar diversos outros saberes que podem ser chamados de pedagógicos. Nesse sentido, Franco sugere o termo "pesquisa-ação" 
como sendo uma alternativa metodológica que o professor consiga construir conhecimentos sobre a prática docente de forma mais original, permitindo um esclarecimento de teorias que são implícitas nas práticas, de modo a favorecer aos sujeitos da prática melhor apropriação crítica da teoria (FRANCO, 2012).

As considerações de Franco sobre o professor como pesquisador ou agente prático resgatam as discussões sobre o perfil do docente de Educação Profissional: antes um profissional do mercado do que um profissional da educação? (PETEROSSI, 2014)

Segundo Peterossi \& Menino (2017), quanto à formação do profissional professor para a educação profissional,

Nunca houve uma proposta realmente consistente em relação a esses professores. $\mathrm{O}$ aspecto profissional em sala de aula é bem evidente desde o início desse ensino, com os 'mestres de ofício professores', até nossos dias, como o 'profissional professor"” (PETEROSSI \& MENINO, 2017, p. 4I).

Na discussão dos autores, há muito tempo os professores que atuam na educação profissional por vezes se utilizam do método imitativo de ensino, restringindo o "conhecimento" dos alunos a uma simples repetição de instruções práticas, que por sua vez foram adquiridas pelos professores na forma de saberes experienciais. A profissão professor, na educação profissional do Estado de São Paulo, passou por diversas modificações e complementações, ficando este profissional sujeito às condicionantes dos tempos sociais.

Data-se de 1935, um marco sobre a discussão da formação deste profissional. O Decreto n.․ 6.942/1935 (SÃO PAULO, 1935) estabeleceu a carreira do magistério técnico profissional, contudo, está carreira só ganhou subsídios de formação na Lei Orgânica Federal de 1942, que instituiu que estes profissionais deveriam receber formações específicas, a serem dadas pelo Ensino Industrial. Tal perspectiva apenas é reconsiderada com a Lei de Diretrizes e Bases da Educação Nacional (LDBEN) de 1961. A LDBEN 4.024/196I (BRASIL, 196I) apresenta em seu artigo 59:

A formação de professores para o ensino médio será feita nas faculdades de filosofia, ciências e letras, e a de professores das disciplinas específicas do ensino médio técnico, em Cursos Especiais de Educação Técnica (BRASIL, 196I)

Essa concepção dicotômica dos professores da educação propedêutica e da educação profissional perdurou até 1968 , quando a Lei n. ${ }^{\circ}$ 5.540/1968 estabeleceu que ambas as formações, para professores das disciplinas gerais ou técnicas, deveriam ser feitas em nível superior. Apesar da aparente equiparação dos dois tipos de profissionais, em 1979 surgiram as possibilidades de cursos de formação pedagógica, que visavam capacitar com saberes pedagógicos os profissionais provindos de outras áreas da atuação para trabalhar nas disciplinas técnicas na educação de nível médio técnico.

Esperava-se que a promulgação na nova LDBEN 9.394/1996 (BRASIL, 1996), com ares da escola nova, pudesse abordar e encerrar por vez a discussão da formação do profissional professor da educação profissional. Entretanto, a Lei, apesar de sustentar a necessidade de formação em nível 
superior para ambos os tipos de professores, não menciona nenhuma vez o professor do ensino técnico. Assim, os cursos de formação pedagógica voltados a diferentes profissionais para o exercício do magistério continuaram vigentes, formando e certificando novos professores. Tamanhas condicionantes fazem com que o professor atuante na educação profissional tenha particularidades ímpares, já que devido a sua natureza profissional, mesclam-se em uma única categoria profissionais provindos dos mais distintos saberes (PETEROSSI \& MENINO, 2017).

Como educação profissional, entende-se que seja a forma de se "educar para o trabalho numa sociedade do conhecimento" (PETEROSSI \& MENINO, 2017, p.8). Além disso, argumenta-se que a educação profissional vai além de apenas fazer com que o jovem aprenda uma profissão, portanto, defende-se que esse tipo de formação é aquela capaz de fornecer competências e habilidades que preparem o aluno, no exercício de uma profissão, a assumir situações que o mundo moderno lhe impõe.

\section{Metodologia da Pesquisa}

Para se atingir os objetivos deste estudo, propõe-se uma pesquisa exploratória, de abordagem qualitativa que, conforme define Minayo (2007), aprofunda-se no mundo dos significados e, por se tratar de uma realidade não visível, precisa ser exposta e interpretada pelos próprios agentes pesquisadores, em primeira instância. Desta forma, foi elaborada uma pesquisa aplicada pela 86

ferramenta Google Forms, com base nos saberes docentes, segundo Tardif (2014), que tratam de saberes, tempo e aprendizagem do trabalho no magistério.

Esta pesquisa foi submetida, por meio eletrônico, a um grupo heterogêneo de professores de uma instituição pública de ensino técnico e tecnológico do estado de São Paulo, de idades e experiências distintas, que atuam em diferentes cursos técnicos, como Contabilidade, Recursos Humanos, Administração e Segurança do Trabalho, de uma unidade de ensino técnico de nível médio, de uma instituição pública do estado de São Paulo. Foi esclarecido a esses sujeitos que a pesquisa era optativa, ou seja, destacou-se que poderiam ou não, responder às questões.

Foram elaboradas perguntas abertas e fechadas, de forma a possibilitar uma melhor análise das perspectivas profissionais do docente, por meio de padrões discursivos. E, em seguida, foi utilizado o programa IRAMUTEQ sobre as respostas dos professores.

\section{Resultados e Discussão}

O questionário, aplicado por meio do Google Forms, constituiu-se de o9 perguntas (o6 fechadas e 03 abertas), sendo respondidas por 18 docentes dos cursos técnicos. Dentre as respostas, foi possível detectar o seguinte perfil: 
Imagem r: Infográfico do Perfil Docente

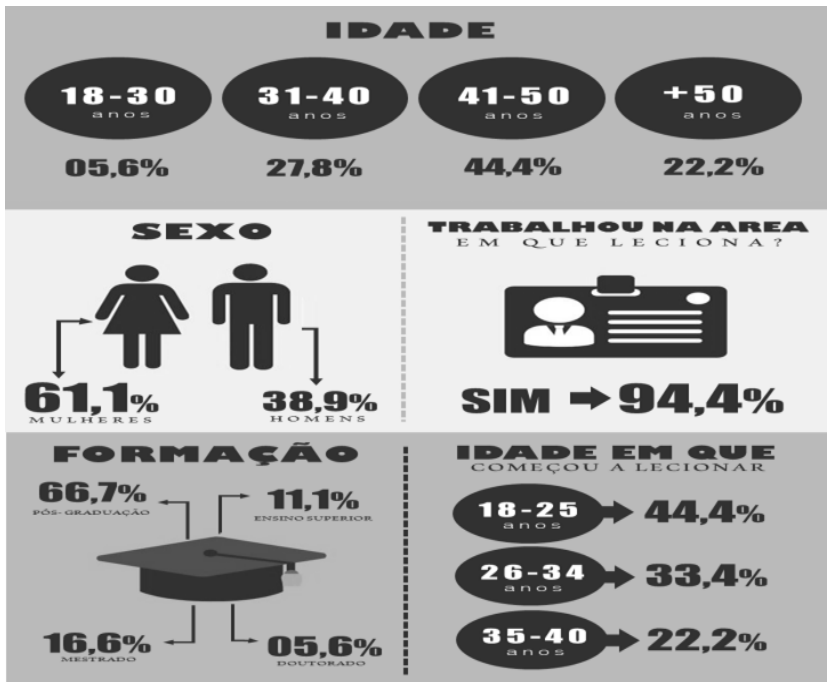

Fonte: Os autores (CANVA. 2020)

Com relação à pergunta: "O que você considera mais importante para ser um bom professor?”, assinalando 03 respostas fechadas, observou-se que as opções: Atualização Profissional $(66,7 \%)$, Experiência Profissional $(55,6)$ e Experiência em sala de aula (50\%), foram as opções mais assinaladas. Essas respostas vão ao encontro das relações que Tardif (2014, p. 63) preconiza: os saberes docentes tais como: os saberes pessoais, da formação escolar, da formação profissional, das fontes secundárias dos livros e matérias didáticos e da experiência profissional, provenientes de diversas fontes de aquisição, auxiliam a integração no trabalho docentes.

Já sobre as 03 respostas fornecidas em forma discursiva foi possível perceber que ainda é presente na fala dos professores a ideia de vocação como ponto importante da profissão e que a: Atualização e Experiências Profissionais são bases de sucesso da profissão. Para Tardif:

[...] o saber dos professores não é só um conjunto de conteúdos cognitivos definidos de uma vez por todas, mas um processo em construção ao longo de uma carreira profissional na qual o professor aprende progressivamente a dominar seu ambiente de trabalho, ao mesmo tempo em que se insere nele e o interioriza por meio de regras de ação que se tornam parte integrante de sua "consciência prática" (TARDIF, 2014, p. 14).

Quanto à primeira pergunta: "O que você acha da afirmação 'qualquer um pode ser professor?”, foi possível identificar os discursos que levam a enxergar a profissão como a arte de dominação de habilidades a serem desenvolvidas, como na resposta: "Em partes, verdadeira. Mas é preciso desenvolver habilidades específicas, como comunicação, empatia e ter um bom psicológico para enfrentar as situações em sala de aula", ou na resposta do professor: "Para ser professor o profissional dever ser paciente, empático e didático. Nem todas as pessoas desenvolvem essas habilidades”. Zabala (1998, p. 13) indica que para ser um bom profissional, ele deve ser "competente em seu ofício", ou seja, o professor 
deve adquirir as competências necessárias através do conhecimento e da experiência adquiridas nas práticas educativas, porém existem muitas variáveis que condicionam esta prática.

Outro professor, complementa ainda que: "tem que ter dedicação" e outro conclui "acredito que com estudo e dedicação a profissão pode ser exercida". Nas respostas ainda foi possível detectar o discurso que enquadra a profissão de professor a uma vocação, como na resposta: "Não concordo... Docência requer vocação" ou "Negativa, pra ser Professor tem que ter o dom".

Ironiza, ainda, outro respondente dizendo que a afirmativa do enunciado é "Uma grande mentira. Qualquer um pode ser médico? Ou engenheiro?”. Tardif tem uma posição bem clara com relação a esta indagação. No sentido de arte de educar o docente se guia através dos ensinamentos, do aprender a educar através de sua experiência, e de suas práticas educativas. Essas questões correspondem ao talento pessoal, de intuição, de experiência, de hábito, de bom senso e de habilidades confirmadas pelo uso.

Foi empregado o software IRAMUTEQ, por meio do qual o "corpus" das perguntas, foi analisado conforme base na frequência de palavras respondidas. Verificou-se portanto, que as palavras: "não concordo", foram as mais mencionadas.

Imagem 2: O que você acha da afirmação 'qualquer um pode ser professor?

\begin{tabular}{|c|c|c|}
\hline Forme & Freq. V & Types \\
\hline não_concordo & 7 & $\mathrm{nr}$ \\
\hline ensinar & 4 & ver \\
\hline verdadeiro & 3 & adj \\
\hline dedicação & 2 & nom \\
\hline desenvolver & 2 & ver \\
\hline domínio & 2 & nom \\
\hline habilidade & 2 & nom \\
\hline professor & 2 & nom \\
\hline profissão & 2 & nom \\
\hline vocação & 2 & nom \\
\hline achar & 1 & ver \\
\hline acreditar & 1 & ver \\
\hline amar & 1 & ver \\
\hline amor & 1 & nom \\
\hline aprendizagem & 1 & nom \\
\hline arte & 1 & nom \\
\hline ativo & 1 & adj \\
\hline aula & 1 & nom \\
\hline bom & 1 & adj \\
\hline caminhada & 1 & nom \\
\hline comunicação & 1 & nom \\
\hline concordar & 1 & ver \\
\hline contato & 1 & nom \\
\hline conteudo & 1 & $\mathrm{nr}$ \\
\hline dedicar & 1 & ver \\
\hline desmerecimento & 1 & nom \\
\hline didático & 1 & adj \\
\hline docência & 1 & nom \\
\hline
\end{tabular}

Fonte: Os autores (IRAMUTEQ versão 0.7 alpha 2, 2019)

A próxima pergunta: "Em poucas palavras, se você pudesse dar um conselho a um professor novato, qual seria?", foi construída uma "nuvem de palavras" com o objetivo de identificar as principais palavras relacionadas aos conselhos dos respondentes aos professores novatos. Pode-se verificar que a preocupação com o "aluno" é quesito central. Já os termos: "atualizar-se”, "aula”, "método" e "estudar", integram os conselhos mais citados, conforme imagem 4. 
Imagem 4: Nuvem de Palavras

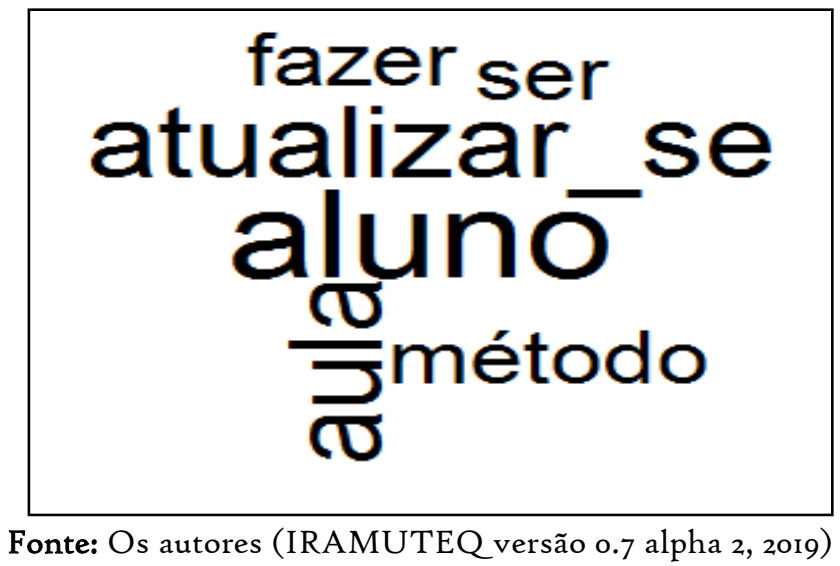

A última pergunta, foi relacionada à indicação da carreira docente: "Você indicaria a carreira de professor a alguém hoje? Por quê?". Verificou-se na imagem 5, que a palavra: "sim", teve o maior número de respostas.

Imagem 5: Formas ativas da pergunta

\begin{tabular}{|l|r|r|}
\hline Forme & Freq. & Types \\
\hline sim & 15 & adv \\
\hline não & 7 & adv \\
\hline muito & 5 & adv \\
\hline porque & 5 & adv \\
\hline professor & 5 & nom \\
\hline carreira & 3 & nom \\
\hline gratificante & 3 & adj \\
\hline mais & 3 & adv \\
\hline profissão & 3 & nom \\
\hline aprender & 2 & ver \\
\hline como & 2 & adv \\
\hline desafio & 2 & nom \\
\hline dever & 2 & ver \\
\hline falta & 2 & nom \\
\hline gosto & 2 & nom \\
\hline importante & 2 & adj \\
\hline indicar & 2 & ver \\
\hline particularmente & 2 & adv \\
\hline sociedade & 2 & nom \\
\hline valorizar & 2 & ver \\
\hline Fonte: Os autores (IRAMUTEQ versão & 0.7 alpha 2, 2019) \\
\hline
\end{tabular}


Fazendo uma análise mais ampla e valendo-se da resposta "sim", observou-se um complemento como "sim, pois existem pessoas com essa vocação" e "Indicaria, caso eu percebesse que a pessoa tem o dom de ensinar". Porém, também foi possível detectar que estas mesmas pessoas demonstraram insatisfações claras com a profissão, principalmente no tocante à valorização.

Para um maior aprofundamento e reflexão, foi realizada também uma análise hierárquica de palavras por similaridade, calculada pelo coeficiente de correlação, utilizada para auxílio na interpretação desta subcategoria. Nota-se na imagem 6, que a palavra "sim", tem uma correlação com os termos: "carreira", "professor" e "gratificante".

Imagem 6: Análise Hierárquica por similaridade

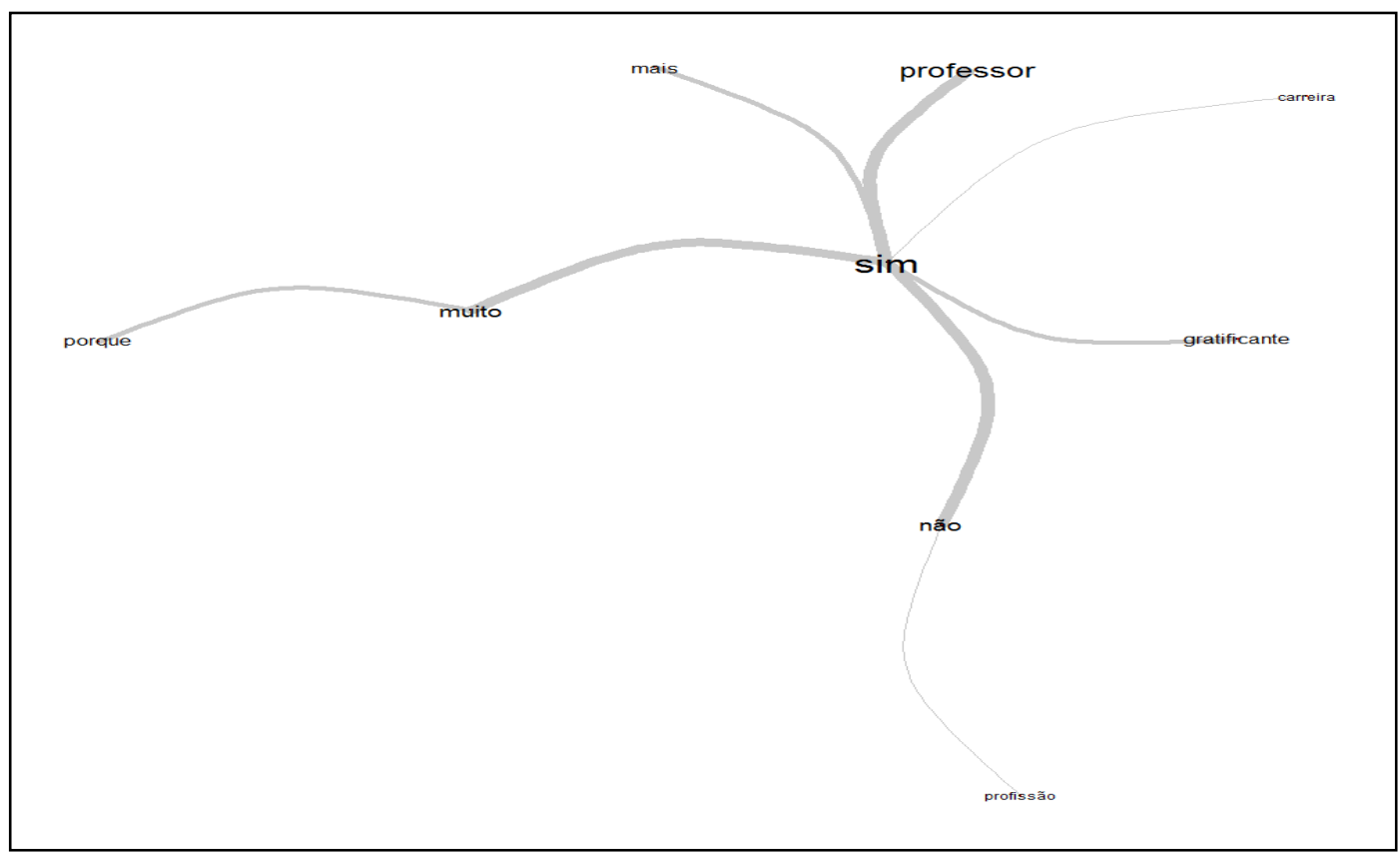

Já nas respostas "não", detectou-se os seguintes enriquecimentos: "não, porque não somos valorizados como deveríamos ser" e "não, pois não há valorização profissional".

Alguns respondentes manifestaram certa satisfação com os desafios que a profissão traz, certos de que é necessária uma preparação para a carreira, como o evidenciado em respostas como:

"sim, porque é uma profissão que tem mais alegrias do que tristezas e é desafiadora e aprendemos muito", ou

"sim, desde que tenha escolhido a carreira por vontade própria e não por falta de oportunidade em outras áreas. Deve ter formação e manter-se sempre atualizado. Considero um dos profissionais mais importantes".

Verifica-se que no processo de formação profissional do professor de ensino técnico e tecnológico, apresentam-se constantes desafios que demandam exigências para a atualização de 
conhecimentos e estudo continuado, no que se refere à formação específica, além da formação pedagógica. No entanto, na percepção dos professores, é possível se verificar a relevância dos saberes docentes profissionais.

\section{Considerações Finais}

A profissão de professor é reconhecida pela sua importância social, entretanto, nota-se através desta pesquisa a clara a desvalorização para com a carreira, principalmente quando se é analisada a questão a partir da perspectiva dos próprios profissionais que a exercem. Atualmente, a Educação Profissional tem ganhado, cada vez mais espaço, no cenário educativo brasileiro, contudo, tal forma de educar requer especificidades de saberes dos profissionais que não se encontram em quaisquer recém-formados.

Através da análise dos dados coletados e das perspectivas dos professores, a respeito da sua profissão com base nos saberes docentes descritos por Tardif, foi possível refletir que os professores compreendem que a profissão "professor" requer experiência em sala de aula e em outras atividades profissionais, além de constante atualização de conhecimentos. Assim, alcançando o objetivo geral desta pesquisa de se analisar perspectivas sobre a profissão docente, foi possível se demonstrar visível a percepção de que a carreira docente é provinda de uma vocação profissional, entretanto, é também considerável uma parcela de professores que reconhecem que a profissão se pauta em habilidades e saberes que são adquiridos, bem como a atualização constante, a preocupação com os alunos, e que 91 apesar dos pontos negativos relacionados a desvalorização da profissão, a carreira ainda é indicada pelos profissionais da educação.

\section{Referências}

ALARCÃO, I. Professores reflexivos em uma escola reflexiva. São Paulo: Cortez, 2003.

BRASIL. Ministério da Educação. Lei de Diretrizes e Bases da Educação Nacional № 4.024, de 20 de dezembro de 196r. Disponível em: https://www2.camara.leg.br/legin/fed/lei/196o-1969/lei-402420-dezembro-196I-353722-publicacaooriginal-I-pl.html Acesso em 20 de março de 2020.

BRASIL. Ministério da Educação. Lei de Diretrizes e Bases da Educação Nacional № 9394, de 20 de dezembro de 1996. Disponível em: http://www.planalto.gov.br/ccivil_03/leis/l9394.htm.

Acesso em 12 de outubro de 2019.

CANVA. Designer gráfico. Disponível em: https://www.canva.com/pt_br/. Acesso em 20 de fevereiro de 2020 .

DELORS, Jacques et al. Educação: um tesouro a descobrir. Io. ed. - São Paulo: Cortez; Brasília, DF: MEC: UNESCO, 2006.

FRANCO, M. A. R. S. Pedagogia e prática docente. I. ed. São Paulo: Cortez, 2012. 
IRAMUTEQ. Interface de $\mathrm{R}$ pour les Analyses Multidimensionnelles de Textes et de Questionnaires. Disponível em: https://sourceforge.net/projects/iramuteq/. Acesso em I2 de setembro de 2019 .

MINAYO, M.C.S. (org). Pesquisa Social. Teoria, Método e Criatividade. 26 ed. Petrópolis, RJ: Editora Vozes, 2007.

NÓVOA, A. Formação de professores e trabalho pedagógico. Lisboa: Educa, 2002. Disponível em: < http://repositorio.ul.pt/handle/10451/3703 >. Acesso em: i7 de maio de 2016.

PETEROSSI; H. G. Subsídios ao estudo da Educação Profissional e Tecnológica. São Paulo: Centro Paula Souza, 2014.

PETEROSSI, H. G.; MENINO, Sérgio E. A formação do formador. São Paulo: Centro Paula Souza, 2017.

PIMENTA, S. G.; ALMEIDA, M. I. de. Pedagogia Universitária: Valorizando o Ensino e a docência na Universidade de São Paulo. São Paulo: Edusp, 2009.

PIMENTA, S. G. Saberes pedagógicos e atividades docentes. $4^{\underline{a}}$ edição. São Paulo: Cortez Editora, 2005 .

ROSE, M. O saber no trabalho - valorização da inteligência do trabalho. ${ }^{\underline{a}}$ edição. São Paulo: Editora Senac, 2007.

SANTOMÉ, J. T. O professorado em época de neoliberalismo: dimensões sociopolíticas de seu trabalho. In: LINHARES, C. (org) Os Professores e a Reinvenção da Escola: Brasil e Espanha. São 92 Paulo: Cortez, 20oI.

SÃO PAULO, Assembleia Legislativa. DECRETO N. 6.942, publicado D.O.E. o6 de fevereiro de 1935. Disponível em: https://www.al.sp.gov.br/repositorio/legislacao/decreto/1935/decreto-694205.02.1935.html. Acesso em I4 de outubro de 2019.

TARDIF, M. Saberes docentes e formação profissional. 17 $7^{\underline{a}}$ edição. Petrópolis: Vozes, 2014.

ZABAlA, A. A Prática Educativa: Como ensinar. Porto Alegre: Artmed, 1998. 